\title{
EnRAGEd about death in type 1 diabetes
}

\author{
T. J. Orchard
}

Received: 4 May 2011 / Accepted: 7 June 2011 /Published online: 3 July 2011

(C) Springer-Verlag 2011

Keywords Advanced glycation end-products · Mortality. Renal disease · Skin fluorescence $\cdot$ Soluble RAGE .

Type 1 diabetes

$\begin{array}{ll}\text { Abbreviations } \\ \text { CAD } & \text { Coronary artery disease } \\ \text { EDC } & \text { Epidemiology of Diabetes Complications } \\ \text { FinnDiane } & \text { Finnish Diabetic Nephropathy } \\ \text { RAGE } & \text { Receptor for AGE } \\ \text { sRAGE } & \text { Soluble receptor for AGE }\end{array}$

The mortality rate for those with type 1 diabetes has declined quite remarkably over the last decades. Recent data from Allegheny County (PA, USA) suggest a 33\% fall in the 30-year mortality rates for those diagnosed with type 1 diabetes as children in the late 1970s, compared with those diagnosed in the early 1960s [1]. Declines have also been reported from Europe [2, 3]. Much of this improvement probably reflects better diabetes management, spurred on by the demonstration of the long-term value of intensive glycaemic management [4, 5] and the advent of selfmonitoring of blood glucose and $\mathrm{HbA}_{1 \mathrm{c}}$ testing. Nonetheless, mortality still remains five to six times higher for those with type 1 diabetes [1] compared with an age-matched community population, and much work remains to be done.

One of the major factors underlying the excess mortality is the development of renal disease [6]. The cumulative

\section{T. J. Orchard $(\square)$}

Department of Epidemiology, Graduate School of Public Health,

University of Pittsburgh,

3512 Fifth Avenue,

Pittsburgh, PA 15213, USA

e-mail: tjo@pitt.edu incidence of end-stage renal disease has shown a parallel fall to that of total mortality, reflecting its large contribution to overall mortality [7]. This link between renal mortality and total mortality has recently been further highlighted by the Finnish Diabetic Nephropathy (FinnDiane) study group, which has reported that all the excess mortality over a 7-year period of follow-up of type 1 diabetes in Finland is seen in those who develop microalbuminuria and more severe proteinuria [8]. The Pittsburgh Epidemiology of Diabetes Complications (EDC) study was recently able to confirm these findings and extend them over a 20-year follow-up [9]. In this study, many of the few deaths in those without microalbuminuria were due to causes other than diabetes [9]. It should be noted, however, that microalbuminuria may represent more than just early stage diabetic nephropathy as it is a strong predictor of cardiovascular disease in the general population [10].

Thus, not only does renal disease itself contribute directly to the premature mortality in type 1 diabetes, it also relates to the development of coronary artery disease in T1D, as was recognised over 20 years ago in reports from the Steno and Joslin clinics [11, 12]. However, with the prevention or delay of renal disease we do not seem to be experiencing as great a fall in cardiovascular disease events as might be expected [7]; rather, it appears that coronary artery disease (CAD) continues to develop but now does so more often without preceding albuminuria. For example, in the Pittsburgh EDC study, over $80 \%$ of those developing CAD in the first 10 years of follow-up had microalbuminuria or more severe proteinuria [13], while in the second decade of follow-up this had fallen to $24 \%$.

What might explain this pattern? It seems likely that the relationship of $\mathrm{CAD} /$ atherosclerosis with glycaemia is more complex than that of other complications, such as 
retinopathy [13]. Furthermore, it has been postulated that insulin resistance may play a major role in CAD in type 1 diabetes [13]. Another likely contributor is the inadequate treatment of standard risk factors, such as blood pressure and lipids [14], which are also present in type 1 diabetes. In addition, the roles of enhanced AGE formation and the receptor for AGE (RAGE) have yet to be fully explored. AGEs, whether measured in tissue [15, 16] or in serum [17], have been known for some time to predict complications. However, this field has been advanced recently with the advent of soluble RAGE (sRAGE) assays. sRAGE is formed by proteolytic cleavage of the membrane-bound RAGE receptor. It lacks the transmembrane and cytoplasmic domain of the regular (full-length) receptor but is measurable in blood [18]. sRAGE is also thought to be protective as it can act as decoy for RAGE ligands $[19,20]$. However, it is not always clear what an increase (or decrease) in sRAGE level means in terms of risk, as illustrated by an important paper by Thomas et al. in this issue of Diabetologia (again, from the FinnDiane study) in which a strong direct relationship is shown between sRAGE and both total and cardiovascular mortality [21]. The findings of Thomas et al. are thus in contrast to those from the general population where an inverse association has been reported with coronary artery disease and atherosclerosis in general $[19,20]$. While there are many potential explanations for these differences, including the differing outcomes (mortality vs morbidity) and confounders that were considered, whether an increased concentration of sRAGE is good or bad may also depend on the setting in which it is measured. In type 2 diabetes an inverse association between levels of sRAGE and RAGE in monocytes has recently been reported, suggesting that in type 2 diabetes RAGE production increases and the sRAGE level decreases [18]. However, the sRAGE level may be so markedly increased in type 1 diabetes that it predominantly reflects the upregulation of the RAGE pathway. For example, in type 1 diabetes the high sRAGE concentration may reflect a general enhancement of RAGE formation, with proportionate cleavage from the membrane to yield a high sRAGE level. In this situation the high sRAGE level may represent increased risk. However, in conditions with a lower overall sRAGE concentration, a higher sRAGE may more closely identify those with a disproportionately high cleavage, i.e. a group with greater protection against RAGE-mediated damage. The current FinnDiane findings [21] are also supported by the results of a report from Spain, where a series of chronic heart failure patients were studied and a direct relationship was seen between sRAGE and both the extent of CAD and the severity of heart failure [22].

Thomas et al. [21] also suggest that the sRAGE prediction is independent of renal disease, providing some contrast to their prior report of no excess mortality without renal disease [8]. However, as subsequent development of renal disease was not accounted for, renal disease may still be part of the pathway and is known to be a powerful determinant of both AGE and RAGE, most likely resulting from decreased AGE clearance [23, 24]. Nonetheless, what does appear to be clear from this latest FinnDiane contribution is that sRAGE is unlikely to be directly causal: the investigators conducted a 'Mendelian randomisation' analysis demonstrating that genetic polymorphisms associated with sRAGE concentrations are not themselves predictive of either total or cardiovascular disease mortality.

These results should provide an impetus to develop further research to better understand how AGEs lead to tissue damage and diabetes complications, with the hope that this central pathway can be appropriately retargeted. This is an exciting time for the field in general, for the assessment of tissue AGEs is becoming more readily feasible by, for example, the measurement of skin AGEs by fluorescence spectrometry. The resulting skin intrinsic fluorescence appears to show stronger associations with neuropathy [25] and coronary artery calcification [26] than do 20-year average $\mathrm{HbA}_{1 \mathrm{c}}$ values. Furthermore, a recent report from the Medalists study of 50-year type 1 diabetes survivors, who are characterised by a remarkable resistance to complications, raises the possibility that there may be some AGE specificity in terms of complication risk and protection [27]. In addition, another recent report, from the EURODIAB prospective study, also of type 1 diabetes, suggests that two plasma AGEs $\left[N^{\varepsilon}\right.$-(carboxyethyl)lysine and pentosidine] predict cardiovascular disease (both fatal and nonfatal) and all-cause mortality [28].

Finally, it is encouraging to note that these exciting observations are not without therapeutic implications, as a number of pharmacological agents appear to have 'AGEmodifying' effects [15]. Angiotensin-receptor blockers, in particular, have been thought to have such properties (recently reviewed in [29]), and thus may represent the beginning of a new wave of RAGE-orientated therapies.

Acknowledgements T.J.O. conceived, wrote and approved this article.

Duality of interest The author declares that there is no duality of interest associated with this manuscript.

\section{References}

1. Secrest AM, Becker DJ, Kelsey SF, Laporte RE, Orchard TJ (2010) All-cause mortality trends in a large population-based cohort with long-standing childhood-onset type 1 diabetes. Diabetes Care 33:2573-2579

2. McNally PG, Raymond NT, Burden MI et al (1995) Trends in mortality of childhood-onset insulin-dependent diabetes mellitus in Leicestershire: 1940-1991. Diabet Med 12:961-966 
3. Borch-Johnsen K (1999) Improving prognosis of type 1 diabetes. Mortality, accidents, and impact on insurance. Diabetes Care 22 (suppl 2):B1-B3

4. The Diabetes Control and Complications Trial Research Group (1993) The effect of intensive treatment of diabetes on the development and progression of long-term complications in insulin-dependent diabetes mellitus. N Engl J Med 329:977986

5. Nathan DM, Cleary PA, Jye-Yu C et al (2005) Intensive diabetes treatment and cardiovascular disease in patients with type 1 diabetes. N Engl J Med 353:2643-2653

6. Secrest AM, Becker DJ, Kelsey SF, LaPorte RE, Orchard TJ (2010) Cause-specific mortality trends in a large population-based cohort with long-standing childhood-onset type 1 diabetes. Diabetes 59:3216-3222

7. Pambianco G, Costacou T, Orchard TJ (2007) the prediction of major outcomes of type 1 diabetes: a 12 year prospective evaluation of three separate definitions of the metabolic syndrome and their components and estimated glucose disposal rate: The Pittsburgh EDC Experience. Diabetes Care 30:1248-1254

8. Groop PH, Thomas MC, Moran JL et al (2009) The presence and severity of chronic kidney disease predicts all-cause mortality in type 1 diabetes. Diabetes 58:1651-1658

9. Orchard TJ, Secrest AM, Miller RG, Costacou T (2010) In the absence of renal disease, 20-year mortality risk in type 1 diabetes is comparable to that of the generation population: a report from the Pittsburgh Epidemiology of Diabetes Complications Study. Diabetologia 53:2312-2319

10. Klausen K, Borch-Johnsen K, Feldt-Rasmussen B et al (2004) Very low levels of microalbuminuria are associated with increased risk of coronary heart disease and death independently of renal function, hypertension, and diabetes. Circulation 110:32-35

11. Jensen T, Borch-Johnsen K, Kofoed-Enevoldsen A, Deckert T (1987) Coronary heart disease in young type 1 (insulin-dependent) diabetic patients with and without nephropathy: incidence and risk factors. Diabetologia 30:144-148

12. Krolewski AS, Warram JH, Christlieb AR, Busick EJ, Kahn CR (1985) The changing natural history of nephropathy in type 1 diabetes. Am J Med 78:785-794

13. Orchard TJ, Costacou T, Kretowski A, Nesto RW (2006) Type 1 diabetes and coronary artery disease. Diabetes Care 29:2528-2538

14. Wadwa RP, Kinney GL, Maahs DM et al (2005) Awareness and treatment of dyslipidemia in young adults with type 1 diabetes. Diabetes Care 28:1051-1060

15. Yu Y, Thorpe SR, Jenkins AJ et al (2006) Advanced glycation endproducts and methionine sulfoxide in skin collagen in type 1 diabetes. Diabetologia 49:2488-2498

16. Monnier VM, Bautista O, Kenny DR et al (1999) Skin collagen glycation, glycoxidation, and crosslinking are lower in subjects with long-term intensive vs conventional therapy of type 1 diabetes: relevance of glycated collagen products $\mathrm{vs} \mathrm{HbA}_{1 \mathrm{c}}$ as markers of diabetic complications. Diabetes 48:870-880
17. Goldin A, Beckman JA, Schmidt AM, Creager MA (2006) Advanced glycation end products: sparking the development of diabetic vascular injury. Circulation 114:597-605

18. Tam XH, Shiu SW, Leng L, Bucala R, Betteridge DJ, Tan KC (2011) Enhanced expression of receptor for advanced glycation end-products is associated with low circulating soluble isoforms of the receptor in type 2 diabetes. Clin Sci (Lond) 120:81-89

19. Falcone C, Emanuele E, D'Angelo A et al (2005) Plasma levels of soluble receptor for advanced glycation end products and coronary artery disease in nondiabetic men. Arterioscler Thromb Vasc Biol 25:1032-1037

20. Lindsey JB, de Lemos JA, Cipollone F et al (2009) Association between circulating soluble receptor for advanced glycation end products and atherosclerosis: observations from the Dallas Heart Study. Diabetes Care 32:1218-1220

21. Thomas MC, Söderlund J, Lehto M et al (2011) Soluble receptor for AGE (RAGE) is a novel independent predictor of all-cause and cardiovascular mortality in type 1 diabetes. Diabetologia doi:10.1007/s00125-011-2186-5

22. Raposeiras-Roubin S, Rodino-Janeiro BK, Grigorian-Shamagian L et al (2010) Soluble receptor of advanced glycation end products levels are related to ischaemic aetiology and extent of coronary disease in chronic heart failure patients, independent of advanced glycation end products levels: New roles for soluble RAGE. Eur J Heart Fail 12:1092-1100

23. Semba RD, Ferrucci L, Fink JC et al (2009) Advanced glycation end products and their circulating receptors and level of kidney function in older community-dwelling women. Am J Kidney Dis 53:51-58

24. Comper WD, Haraldsson B, Deen WM (2008) Resolved: normal glomeruli filter nephrotic levels of albumin. J Am Soc Nephrol 19:427-432

25. Conway BN, Aroda VR, Maynard JD et al (2011) Skin intrinsic fluorescence correlates with autonomic and distal symmetrical polyneuropathy in individuals with type 1 diabetes. Diabetes Care 34:1000-1005

26. Conway B, Edmundowicz D, Matter N, Maynard J, Orchard T (2010) Skin fluorescence correlates strongly with coronary artery calcification severity in type 1 diabetes. Diabetes Technol Ther 12:339-345

27. Sun JK, Keenan HA, Cavallerano JD et al (2011) Protection from retinopathy and other complications in patients with type 1 diabetes of extreme duration. The Joslin 50-Year Medalist Study. Diabetes Care 34:968-974

28. Nin JW, Jorsal A, Ferreira I et al (2011) Higher plasma levels of advanced glycation end products are associated with incident cardiovascular disease and all-cause mortality in type 1 diabetes. A 12-year follow-up study. Diabetes Care 34:442-447

29. Grossin N, Boulanger E, Wautier MP, Wautier JL (2010) The different isoforms of the receptor for advanced glycation end products are modulated by pharmacological agents. Clin Hemorheol Microcirc 45:143-153 